\title{
Bibliometric positioning of scientific manufacturing journals: a comparative analysis
}

\author{
Fiorenzo Franceschini • Domenico Maisano
}

Received: 16 April 2010/Published online: 26 October 2010

(C) Akadémiai Kiadó, Budapest, Hungary 2010

\begin{abstract}
This article analyzes some of the most popular scientific journals in the Manufacturing field from the point of view of four bibliometric indicators: the ISI impact factor (ISI-IF), the Hirsch (h) index-for-journal, the total number of citations and the h-spectrum. h-spectrum is a novel tool based on h, making it possible to (i) identify a reference profile of the typical authors of a journal, (ii) compare different journals and (iii) provide a rough indication of their "bibliometric positioning" in the scientific community. Results of this analysis can be helpful for guiding potential authors and members of the scientific community in the Manufacturing area. Of particular interest is the construction of maps based on h-spectrum and ISI-IF to compare journals and monitor their bibliometric positioning over time. A large amount of empirical data are presented and discussed.
\end{abstract}

Keywords Citations - Manufacturing journal · Hirsch index · Hirsch spectrum • Impact factor · Journal authors · Bibliometrics

\section{Introduction}

In the world of scientific research there is a large number of journals, which represent the natural destination of the output of researchers. These journals cover many different scientific disciplines and can be differentiated by subject/topic of interest, reputation and popularity within the scientific community. Although representing just a portion of the Engineering field, Manufacturing encompasses several scientific journals, constantly growing in number. Considering the perspective of a researcher of this area, many questions may be raised: "What criteria can be used to evaluate and compare different Manufacturing journals?", "How is it possible to find rough information on the author population of each Manufacturing journal?", "What is the bibliometric positioning of different Manufacturing journals and their influence on the scientific community?"

F. Franceschini $(\bowtie) \cdot$ D. Maisano

Dipartimento di Sistemi di Produzione ed Economia dell'Azienda (DISPEA), Politecnico di Torino,

Corso Duca degli Abruzzi 24, 10129 Turin, Italy

e-mail: fiorenzo.franceschini@polito.it 
Answering the previous questions is not easy. There are many ways to monitor, compare and study how scientific journals change over the years, like considering their circulation, the reputation/prestige of the editorial board or the presence of articles submitted by eminent authors. However, these evaluations are often subjective and not very reliable. A more objective tool for this purpose can be represented by bibliometric indicators, which are based on citation statistics. Although indicators can show some weak points, most of the time they seem to be the main way for evaluating, comparing and ranking scientific journals (Garfield 2006; Leydesdorff 2009; Mingers 2009).

The goal of this paper is to analyse some of the major Manufacturing journals from the point of view of four bibliometric indicators, respectively the ISI impact factor (ISI-IF), the Hirsch (h) index for journals, the total number of citations (C) and the h-spectrum. ISI-IFalong with other very diffused indicators like cited half-life and immediacy index-is evaluated only for journals indexed by Thomson Scientific (Amin and Mabe 2000; Thomson Reuters 2010). h-index-for-journals and C are other relatively diffused citationbased indicators, whereas h-spectrum has been recently introduced in order to complement the others (Hirsch 2005; Franceschini and Maisano 2010a, b). Differently from ISI-IF, the last three indicators are applicable to every kind of journal. In particular, h-spectrum can be used for several practical purposes:

- to define the profile of the "typical authors" of a specific journal. This profile may represent a reference for other (potential) authors;

- to help a journal's editorial board to periodically monitor the effect of the paper selection policy, from the viewpoint of the population of the journal authors. In this sense, h-spectrum may become an indicator of editorial strategy;

- to provide a rough indication on the bibliometric positioning of a journal on the scientific community.

All the four indicators are based on citation statistics and they should not be used for comparing journals of different disciplines (e.g. Medicine, Physics, Engineering, Mathematics etc.), owing to the different citation rates (Antonakis and Lalive 2008).

The present analysis can be helpful for guiding potential authors and members of the scientific (academic) community in the Manufacturing area. A parallel study has been recently carried out in the field of Quality Engineering/Management (Franceschini and Maisano 2010a).

The remaining of this paper is organised into four sections. "Bibliometric indicators" section provides a description of the bibliometric indicators that are used in the analysis. "Methodology" section focuses on the analysis methodology. "Empirical data analysis" section presents some analysis results and reflections about them. "Remarks on the combined use of different bibliometric indicators" section contains a proposal for using h-spectrum and ISI-IF complementarily. Finally, conclusions are given, summarising the original contribution of the paper.

\section{Bibliometric indicators}

Indicators that are used in the analysis are briefly described in the following subsections. A close examination of the mathematical basis underlying most of these (and other) bibliometric indicators is presented in Glänzel (2010) and Glänzel and Schubert (2010). 
ISI-IF

The ISI-IF was created in the $1960 \mathrm{~s}$ as a way to measure the value of scientific journals. For a particular journal and year, ISI-IF is computed by calculating the average number of citations to articles published in the journal during the preceding 2 years, from all articles published in that given year (Garfield 2005). Unfortunately, ISI-IF is more often misused (JCQAR 2010). The most insidious misuse is represented by the growing tendency to compare individual papers, people, programs, or even disciplines, ascribing the properties of an individual journal to each article within that journal (and to each author). In other words, it should be pointed out that if the ISI-IF of journal $\mathrm{A}$ is greater than that of journal B, then a paper in A is not necessarily superior to a paper in $\mathrm{B}$, and the author of the paper in $\mathrm{A}$ is not necessarily superior to the author of the paper in B.

ISI-IF values of the indexed journals are annually reported in the journal citation reports (JCR) by Thomson Scientific (Thomson Reuters 2010).

h-index

The h-index is a relatively recent bibliometric indicator for evaluating the scientific productivity and diffusion of one author in terms of publications and citations respectively. $h$ is defined as the number such that, for one author's publications, h publications received at least $\mathrm{h}$ citations while the other publications received no more than $\mathrm{h}$ citations (Hirsch $2005,2007)$. In general, the larger $\mathrm{h}$, the larger the diffusion and prestige of one author in the scientific community.

A peculiarity of $h$ is that it cannot decrease with time. In fact, it synthesises the number of papers and the corresponding number of citations, and both these variables do not decrease over time. For example, in case of career interruption or retirement, the h-index of one author remains constant or may increase (if already published papers accumulate new citations). The negative consequence of this fact is that $h$ is not perfectly suitable to compare scholars with different seniority, being in favour of those with long careers (Mingers 2009).

Ever since its introduction, $h$ received much attention and also some criticism; in any case it has the unquestionable merit of being simple, synthetic and robust (Moed 2005; Egghe 2006, 2010; Glänzel 2006a; Kelly and Jennions 2006; Saad 2006; Bornmann and Daniel 2007; Costas and Bordons 2007; Franceschini et al. 2007; Orbay et al. 2007; Schreiber 2007; Wendl 2007; Harzing and van der Wal 2008; Alonso et al. 2009; Van Raan 2006; Rousseau 2010; Franceschini and Maisano 2010c). Another tangible sign of the popularity of $\mathrm{h}$ is the appearance of many proposals for new variants and improvements (Banks 2006; Batista et al. 2006; Braun et al. 2006; BiHui et al. 2007; Burrell 2007; Katsaros et al. 2007; Sidiropoulos et al. 2007; Antonakis and Lalive 2008; Woeginger 2008; Franceschini and Maisano 2009; Lehmann et al. 2010; Schreiber 2010; Franceschini et al. 2010).

Braun et al. (2006) proposed using the h-index for evaluating and comparing scientific journals as well. In detail, the h-for-journal is the number such that, for the group of articles published by the journal in a precise time period (e.g. 1 year), $h$ articles received at least $h$ citations while the others received no more than $\mathrm{h}$ citations. Thus, the way of calculation is the same as for $\mathrm{h}$, with the only exception that the articles are related to a journal in a specific publication period. 
Total number of citations

$\mathrm{C}$ is the total number of citations so far received by the journal issue(s) published in a specific period (e.g. in 1 year). This information is immediately available from the most diffused search engines (i.e. Google Scholar, Web of Science and Scopus) and does not require any calculation (Harzing and van der Wal 2008; Scopus-Elsevier 2010; Thomson Reuters 2010).

\section{h-spectrum}

$\mathrm{h}$-spectrum is defined as the distribution representing the $\mathrm{h}$ values associated to the authors (and co-authors) of a specific journal, considering a specific publication period (Franceschini and Maisano 2010b). The term "spectrum" is originated from the fact that this distribution provides an image of the journal author population in a precise time period. Advantages of this new indicator are discussed later on. h-spectra will be constructed according to the following assumptions/conventions:

- All the different (co-)authors of one journal have the same importance. Thus, their $\mathrm{h}$-indexes are not weighted in inverse proportion to the number of (co-)authors of the corresponding paper(s).

- The h-index of an author, who publishes more than one article in a journal during the period of interest, is counted (only) once.

- For simplicity, the h-index of each author is calculated taking into account the scientific publications and citations accumulated up to the moment of the analysis. In fact, it should be remarked that the h-index of a scientist tends to increase over time, because of the gradual accumulation of publications/citations. With a bit more effort - the analysis can be developed considering the publications/citations accumulated up to the journal publication date, excluding the subsequent ones. However, since the average time growth rate of h-index is relatively small (in engineering disciplines especially), the real variations in the h-spectra would be reasonably limited (Burrell 2007). To avoid any misunderstanding, when calculating a journal's h-spectrum two parameters have to be stated: (i) the period of interest in which the journal authors are identified (e.g. the whole year 2009) and (ii) the precise moment in which author h-indexes are calculated (in our case, December 2009).

\section{Methodology}

Journals are selected from those listed in the JCR of 2008 (issued in June 2009), considering the ISI subject category of Manufacturing (Thomson Reuters 2010). Initially, we intended to analyze all the 38 listed journals, but 15 of them have been later excluded because of the difficulty in disambiguating the authors (this aspect is clarified at the end of this section).

Finally, 23 journals-belonging to different publishers-have been selected (see Table 1). Also, Table 1 reports the journal acronyms used hereafter in the text. For each journal we determine ISI-IF, h, C, and the h-spectrum relative to different years.

Apart from ISI-IF, citation statistics are collected using Google Scholar (GS) as search engine. It was decided to use this database (i) because of its greater coverage (GS also includes citations to books, book chapters, dissertations, working papers, conference paper, 
Table 1 List of the 23 Manufacturing journals selected for the analysis

\begin{tabular}{|c|c|c|}
\hline Journal name & Acronym & Publisher \\
\hline Assembly Automation & AA & Emerald \\
\hline $\begin{array}{l}\text { International Journal of Artificial Intelligence for Engineering } \\
\text { Design, Analysis and Manufacturing }\end{array}$ & AI EDAM & Cambridge University Press \\
\hline Composites Part A: Applied Science and Manufacturing & ASM & Elsevier \\
\hline Concurrent Engineering Research and Applications & CERA & SAGE Publications \\
\hline Design Studies & DS & Elsevier \\
\hline Human Factors and Ergonomics in Manufacturing & HFEM & John Wiley \& Sons \\
\hline International Journal of Advanced Manufacturing Technology & IJAMT & Springer \\
\hline International Journal of Machine Tools and Manufacture & IJMTM & Elsevier \\
\hline International Journal of Production Economics & IJPE & Elsevier \\
\hline International Journal of Production Research & IJPR & Taylor \& Francis \\
\hline $\begin{array}{l}\text { Journal of Computing and Information Science } \\
\text { in Engineering }\end{array}$ & JCISE & ASME Digital Library \\
\hline Journal of Intelligent Manufacturing & JIM & Springer \\
\hline Journal of Materials Processing Technology & JMPT & Elsevier \\
\hline Journal of Manufacturing Science and Engineering & JMSE & ASME Digital Library \\
\hline Journal of Scheduling & JS & Springer \\
\hline Materials and Manufacturing Processes & MMP & Taylor \& Francis \\
\hline Machining Science and Technology & MST & Taylor \& Francis \\
\hline Precision Engineering & $\mathrm{PE}$ & Elsevier \\
\hline Production and Operations Management & POM & John Wiley \& Sons \\
\hline Packaging Technology and Science & PTS & John Wiley \& Sons \\
\hline Robotics and Computer-Integrated Manufacturing & RCIM & Elsevier \\
\hline Research in Engineering Design & RED & Springer \\
\hline Soldering \& Surface Mount Technology & SSMT & Emerald \\
\hline
\end{tabular}

Journals are sorted in alphabetical order with respect to the journal acronym

and journal articles published in non-ISI and Open-Access journals) and (ii) since it can be automatically queried through dedicated software applications, such as Publish or Perish or other ad hoc applications (Harzing and Van der Wal 2008). Nevertheless, the analysis can be repeated using other databases, like Web of Science or Scopus. It is worth mentioning that in the Web of Science, the indicators of a given journal/scientist can be obtained by few clicks, by using the Analyze Results feature (Thomson Reuters 2010). Unfortunately, search is limited to citing papers published on journals/proceedings that are listed by Thomson Scientific. This is the reason why we did not use this tool.

A crucial problem encountered in our analysis is represented by homonym scientists/ authors. In general, authors with common names or authors identified only by the surname and the first name initials - rather than full first name(s) - are subject to this kind of problem. The practical effect is that contributions of different homonym authors are erroneously added up, with the result of "inflating" one author's h. For this reason, 15 of the 38 Manufacturing journals indexed by Thomson Scientific have been a priori excluded from the analysis. Also, considering the 23 examined journals, some authors with common names and only first name(s)' initial(s) have been found. Luckily, these "suspected" authors can be detected and then excluded from the analysis quite easily. However, since they represent just a small part of the available information, the loss of information is not 
significantly relevant for our purpose. All the indicators are calculated taking into account the citations accumulated up to the moment of the analysis (in this case, December 2009).

\section{Empirical data analysis}

\section{ISI-IF viewpoint}

Table 2 contains the ISI-IF values for the 23 Manufacturing journals in five consecutive years, from 2004 to 2008. It can be noticed that, for most of the journals, ISI-IF values are gradually increasing over the years. Some of the possible reasons of this behaviour are discussed by Althouse et al. (2010). On average, the ISI-IF values of the examined journals are contained between 0.240 and 1.616 .

h-for-journal and $\mathrm{C}$ viewpoint

Figures 1 and 2 represent the values of h-for-journal and $\mathrm{C}$ for the 23 Manufacturing journals in Table 1 in 21 consecutive years (from 1989 to 2009). For example, in the year 2002 PE's $h$ is 16, meaning that the 16 most cited articles published in PE have received at

Table 2 ISI-IF values related to 23 Manufacturing journals in five consecutive years (from 2004 to 2008)

\begin{tabular}{|c|c|c|c|c|c|c|}
\hline Journal & 2004 & 2005 & 2006 & 2007 & 2008 & Mean (2004-2008) \\
\hline AA & 0.084 & 0.061 & 0.307 & 0.368 & 0.382 & 0.240 \\
\hline AI EDAM & 0.156 & 0.128 & 0.405 & 0.279 & 0.477 & 0.289 \\
\hline ASM & 1.145 & 1.446 & 1.875 & 1.662 & 1.951 & 1.616 \\
\hline CERA & 0.418 & 0.255 & 0.569 & 0.482 & 0.611 & 0.467 \\
\hline DS & - & - & 0.807 & 1.017 & 1.115 & 0.980 \\
\hline HFEM & 0.356 & 0.239 & 0.245 & 0.420 & 0.434 & 0.339 \\
\hline IJAMT & 0.352 & 0.406 & 0.418 & 0.378 & 0.743 & 0.459 \\
\hline IJMTM & 1.183 & 1.057 & 1.184 & 1.120 & 1.576 & 1.224 \\
\hline IJPE & 0.879 & 1.008 & 1.183 & 0.995 & 2.026 & 1.218 \\
\hline IJPR & 0.558 & 0.481 & 0.799 & 0.560 & 0.774 & 0.634 \\
\hline JCISE & - & - & 0.531 & 0.446 & 0.807 & 0.595 \\
\hline JIM & 0.595 & 0.343 & 0.598 & 0.419 & 1.018 & 0.595 \\
\hline JMPT & 0.578 & 0.592 & 0.615 & 0.816 & 1.143 & 0.749 \\
\hline JMSE & 0.577 & 0.532 & 0.536 & 0.595 & 0.740 & 0.596 \\
\hline JS & 0.660 & 0.852 & 0.811 & 1.000 & 1.050 & 0.875 \\
\hline MMP & 0.472 & 0.536 & 0.606 & 0.612 & 0.706 & 0.586 \\
\hline MST & 0.347 & 0.500 & 0.352 & 0.621 & 0.684 & 0.501 \\
\hline PE & 0.796 & 0.853 & 0.829 & 0.733 & 0.895 & 0.821 \\
\hline POM & 0.444 & 0.831 & 2.516 & 2.123 & 1.933 & 1.569 \\
\hline PTS & 0.362 & 0.397 & 0.552 & 0.923 & 1.030 & 0.653 \\
\hline RCIM & 0.699 & 0.638 & 0.810 & 0.804 & 1.371 & 0.864 \\
\hline RED & 1.114 & 0.781 & 0.667 & 0.517 & 1.320 & 0.880 \\
\hline SSMT & 0.658 & 1.212 & 1.194 & 0.727 & 0.667 & 0.892 \\
\hline
\end{tabular}

Data are excerpted from the JCRs of the corresponding years (Thomson Reuters 2010). DS and JCISE were not indexed by Thomson Scientific before 2006 

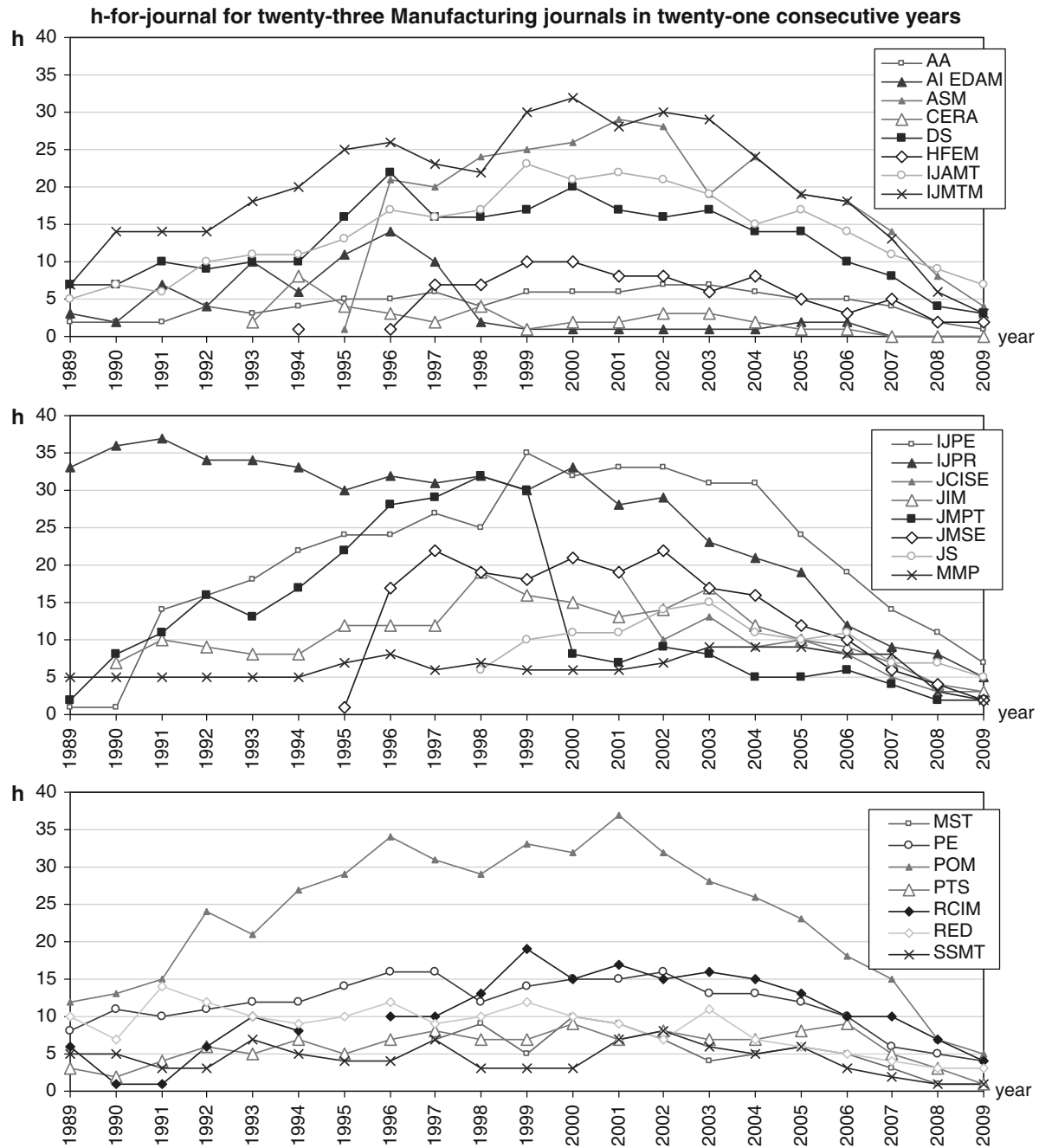

Fig. 1 h-for-journal values for the 23 Manufacturing journals (see Table 1), in 21 consecutive years (from 1989 to 2009). Values are calculated taking into account the citations accumulated up to the moment of the analysis (December 2009). For the purpose of readability, journal profiles are first sorted in alphabetical order with respect to the journal acronyms and then divided in three groups

least 16 citations each. Journals with the higher h-for-journal and C profiles are ASM, DS, IJAMT, IJMTM, IJPE, IJPR, PE and POM.

In general, h-for-journal and $\mathrm{C}$ have quite similar patterns. The corresponding empirical correlation is represented in Fig. 3, taking into account three of the 23 examined journals. Considering the scientific production of one scholar, Hirsch empirically showed that $\mathrm{C}$ is approximately proportional to $\mathrm{h}^{2}$ (Hirsch 2005). Analysing the patterns in Fig. 3, this behaviour roughly seems to apply to the h-for-journal as well.

From 1995 to 1999 , the C profile of JMPT looks rather high and nervous, with two peaks that fall beyond the upper limit of the vertical axis scale. The reason is that in this period the journal had been publishing a large number of articles with many received 

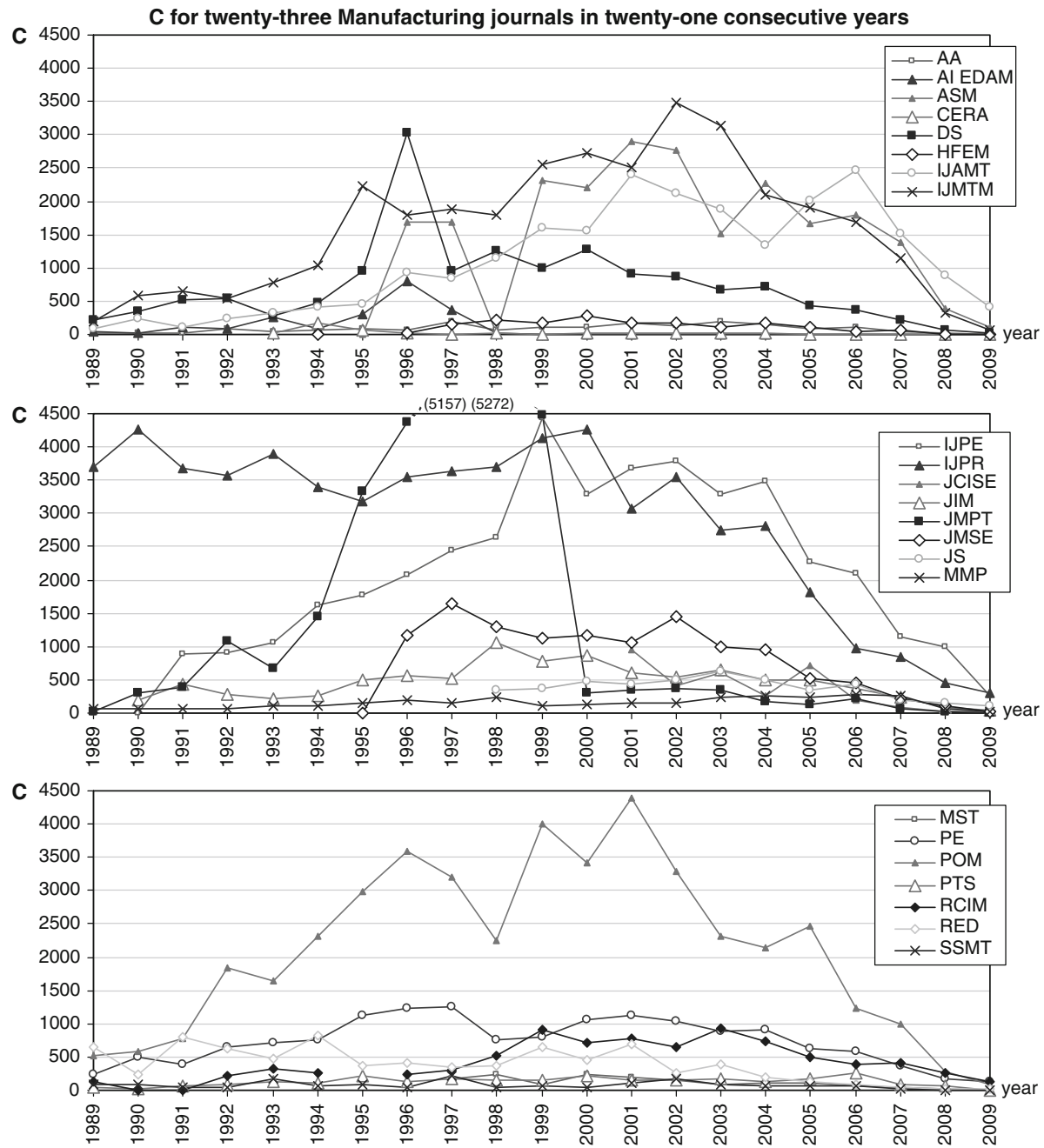

Fig. $2 \mathrm{C}$ values for the 23 Manufacturing journals (see Table 1), in 21 consecutive years (from 1989 to 2009). Values are calculated taking into account the citations accumulated up to the moment of the analysis (December 2009). For the purpose of readability, journal profiles are first sorted in alphabetical order with respect to the journal acronyms and then divided in three groups. In 1997 and 1998, the profile of JMPT has two peaks falling beyond the upper limit of the vertical axis scale. The corresponding numeric values are reported in brackets

citations. The sudden drop in $\mathrm{C}$ after 1999 is due to a strong reduction of the number of articles published every year by the journal (from about 500 to about 200). The JMPT's hfor-journal profile is a bit less nervous, since h-for-journal is more insensitive to accidental excess of lowly and highly cited articles (Orbay et al. 2007). Profiles of ASM, CERA, HFEM, JCISE, JIM, JMSE, JS and MST are not complete since these journals appeared for the first time after 1989. Besides, RCIM was not issued during 1995. 

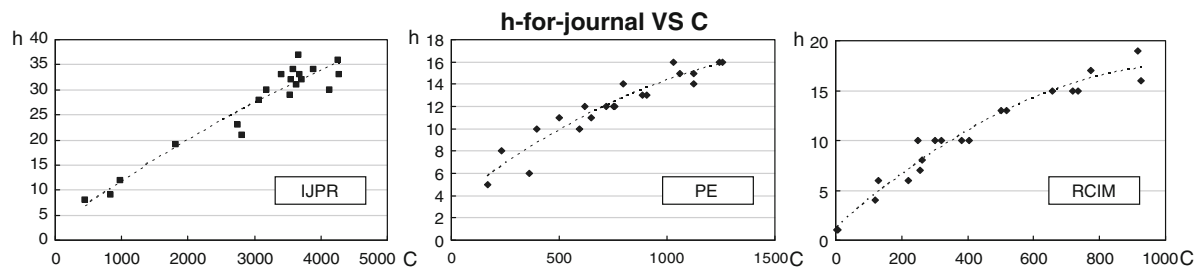

Fig. 3 Relationship between h-for-journal and C considering data related to three Manufacturing journals (i.e. IJPR, PE and RCIM), over 21 consecutive years (from 1989 to 2009). Hirsch empirically showed that, for one researcher, $\mathrm{C}$ is approximately proportional to $\mathrm{h}^{2}$ (Hirsch 2005). This behaviour seems to apply also to the h-for-journal and can be extended to the remaining journals

h-for-journal and $\mathrm{C}$ can be used to compare different journals. It must be pointed out that citation accumulation of one article requires a certain amount of time to become stable. According to some authors, about 5-6 years for journals in the management/ engineering field (Amin and Mabe 2000; Castillo et al. 2007; Harzing 2010). This "physiological" behaviour is well represented in Figs. 1 and 2 and applies to most of the journals: in the last years (e.g. from 2004 to 2009), h-for-journal and C values tend to decrease and are significantly smaller than in the previous years. Thus, h-for-journal and $\mathrm{C}$ are not suitable to evaluate the most recently published journals and, much less, to compare them with other older publications. Besides, being sensitive to the number of articles per issue, if calculated on a yearly basis, $\mathrm{h}$-for-journal and $\mathrm{C}$ tend to favour journals with many articles/issues per year.

Apart from the last 5-6 years, most of the h-for-journal values are included between 5 and 25. Similarly, most of the journal $C$ values are included between 100 and 2,500. Figure 4 shows the journal h-for-journal and $\mathrm{C}$ mean values and the corresponding standard deviations (respectively $s_{\mathrm{h}}$ and $s_{\mathrm{C}}$ ), in the years 1989-2003.

\section{h-spectrum viewpoint}

The h-spectrum analysis can be divided in two distinct activities:

- construction and comparison of the h-spectra related to the 23 journals in the same reference year (i.e. 2009), so as to investigate how the h-spectrum changes from journal to journal;

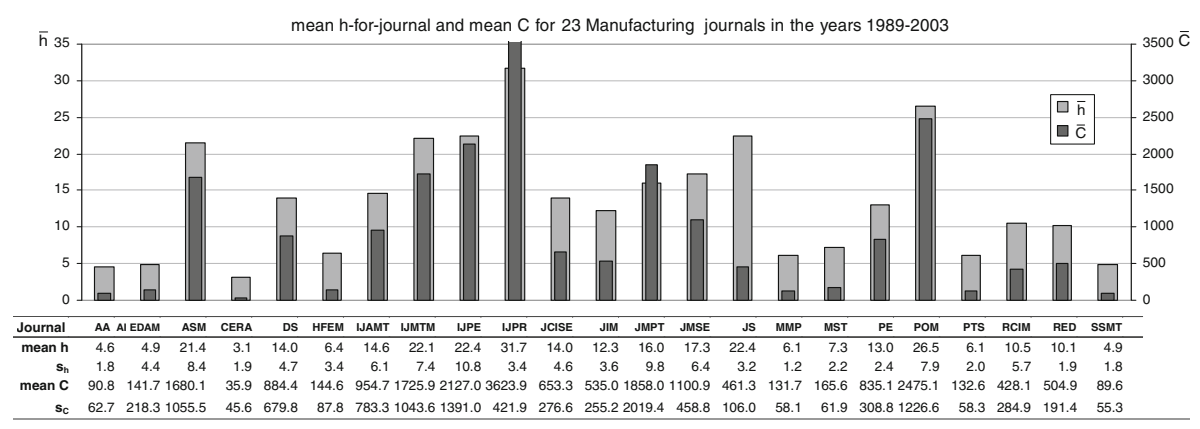

Fig. $4 \mathrm{~h}$-for-journal and $\mathrm{C}$ mean values and corresponding standard deviations-respectively $s_{\mathrm{h}}$ and $s_{\mathrm{C}}-$ for 23 Manufacturing journals, in the years 1989-2003 
- construction and comparison of the h-spectra related to the same journal(s) in six consecutive years (precisely, from 2004 to 2009), so as to investigate how a journal's h-spectrum tends to change over time.

Analysis in the year 2009

For each journal, we identify the authors of papers published in 2009. Then, the h-indexes of the individual authors are calculated. Finally, the distribution of the authors' h-indexes is constructed. The output of this analysis is illustrated in Fig. 5, showing the h-spectra related to the journals in Table 1 .

At a first glance, all these distributions are right-skewed and have a characteristic profile, which is approximately decreasing. Analysing the distributions in more detail, some interesting aspects emerge. Figure 6 shows the authors' h-index average value $(\overline{\mathrm{h}})$, the corresponding standard deviation (s) and the number of authors $(\mathrm{N})$ associated to each
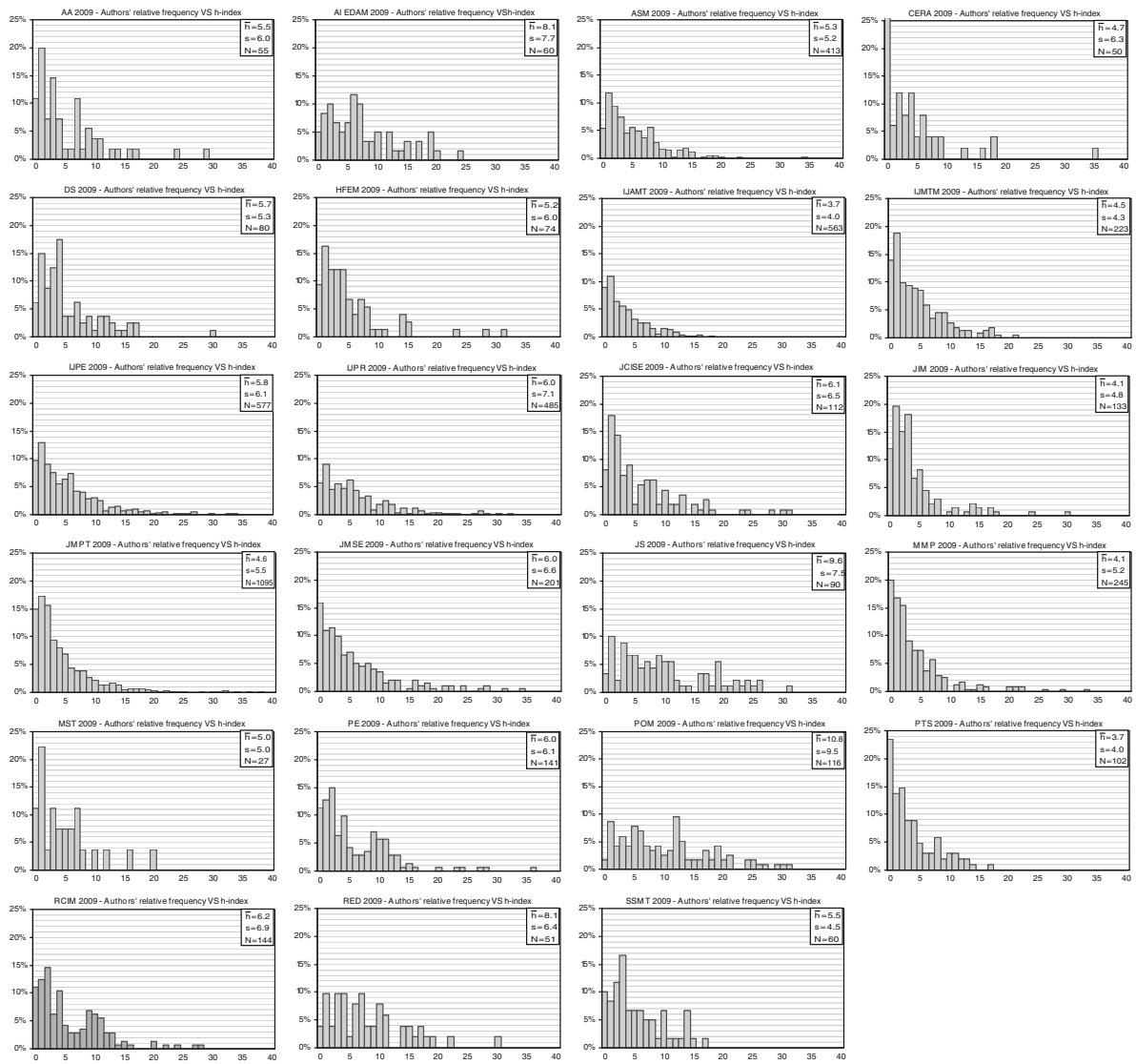

Fig. 5 h-spectra (authors' relative frequency VS h-index) for 23 Manufacturing journals (see Table 1), in the year 2009. For each journal, the authors' h-index average value $(\bar{h})$, the corresponding standard deviation (s) and the number of authors $(\mathrm{N})$ are reported. Spectra are sorted in alphabetical order with respect to their acronyms 
journal. Journals are sorted in descending order with respect to $\bar{h}$. It can be seen that, despite their similar shape, distributions are appreciably different in terms of values of $\overline{\mathrm{h}}$ and $\mathrm{s}$.

Furthermore, it is interesting to notice that - considering the same journal $-\overline{\mathrm{h}}$ and s have generally similar values. Their empirical correlation is nearly linear with a rather high coefficient of determination $\left(R^{2}=0.76\right.$, see Fig. 7). Let us try to justify this result. Looking at Fig. 6, the vast majority of authors have relatively low values of $h$ (say less than 10-15). This applies to all journal h-spectra. Considering a generic h-spectrum, the presence of authors with relatively high h-values (say above 15-20) will therefore make the distribution expand to the right, inducing an increase in the corresponding $\overline{\mathrm{h}}$ and $\mathrm{s}$ values. Realistically, this is the reason why both $\bar{h}$ and s tend to increase for those h-spectra with a relatively heavy right tail. A more formal justification of this correlation could be formulated after constructing a suitable h-spectrum mathematical model, based on common approaches in bibliometrics (Egghe and Ravichandra Rao 2001; Burrell 2002; Glänzel 2006b).

Going back to the analysis, there is no empirical correlation between $\overline{\mathrm{h}}$ and $\mathrm{N}$ or s and $\mathrm{N}$ $\left(R^{2} \approx 0\right)$. On the basis of this result, it seems quite appropriate using $\overline{\mathrm{h}}$ as a synthetic indicator to perform quick evaluations and comparisons among different h-spectra.

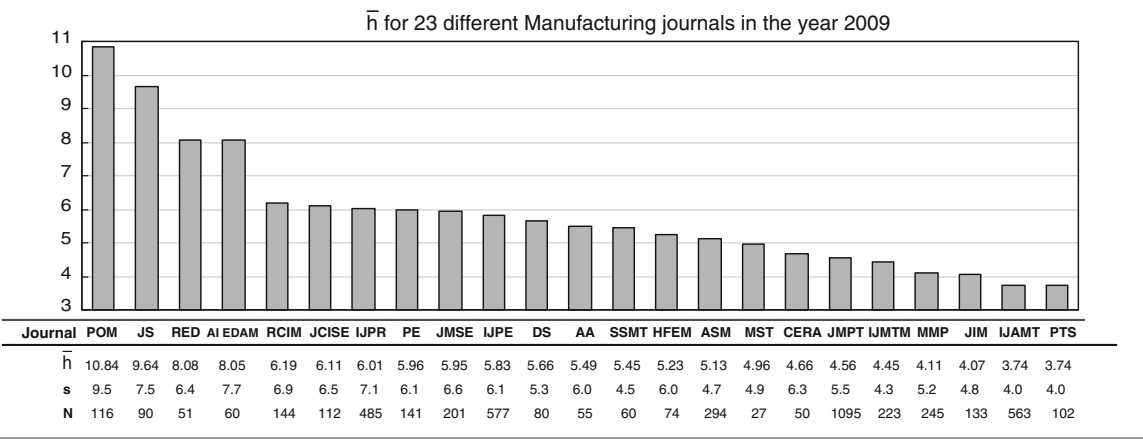

Fig. 6 Synthetic results of the analysis of 23 Manufacturing journals, in the year 2009. The table reports the $\overline{\mathrm{h}}, \mathrm{s}$ and $\mathrm{N}$ values relative to each journal. In the bar-chart, journals are sorted in descending order with respect to $\bar{h}$

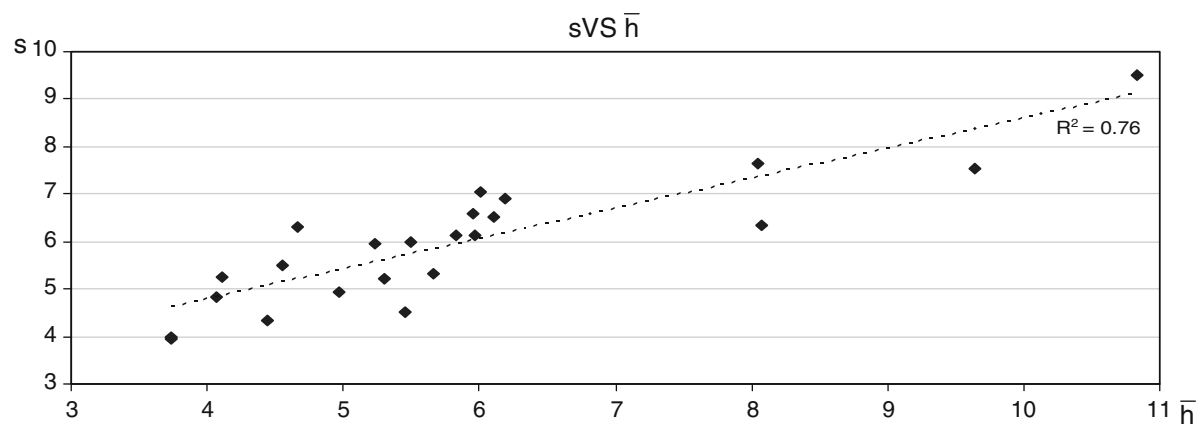

Fig. 7 Relationship between $s$ and $\bar{h}$ related to the h-spectra in Fig. 5 
The second part of this analysis is aimed at finding how h-spectra changes over time. To this purpose, the construction of the journal h-spectrum is extended to six consecutive years (from 2004 to 2009). For simplicity, Fig. 8 reports the resulting spectra concerning only three of the previous 23 journals (IJPR, PE and RCIM).

For IJPR and RCIM, h-spectra look relatively robust and stable over the six examined years. Differently, PE shows some fluctuations in $\overline{\mathrm{h}}$ values. $\overline{\mathrm{h}}, \mathrm{s}$ and $\mathrm{N}$ values for all the 23 journals are synthesised in Table 3 . Focusing the analysis on $\bar{h}$ values, the corresponding journal profiles can be divided into two qualitative groups (see Fig. 9):

1. Stable $-\overline{\mathrm{h}}$ profiles are almost flat, with moderate fluctuations over the years;

2. Nervous-Irregular profiles with more pronounced variations

It can be noticed that $\overline{\mathrm{h}}$ values of the journals of group one are generally smaller than the others', while journals of group two are qualitatively more variable than the others. Possible variations in one journal profile are due to (i) change of the journal editorial board, (ii) variation of the article selection policy, (iii) appearance of new competing journals, (iv) presence of special issues, etc.

Apart from the journals of group two, it can be said that profiles are generally stable. Two possible reasons of the profiles' relative stability are:

- authors of a particular journal tend to be "attracted" to it over the years;

- the editorial board policy tends to be consistent over time.

Since, there can be some variations from one year to the next, we noticed that the characteristic shape of one journal's h-spectrum becomes more and more consolidated by increasing the reference time period. This aspect is shown in Fig. 10, reporting the h-spectra for three of the 23 Manufacturing journals, in four different time periods $(1,2,4$ and 6 years, respectively). Numerical data related to the h-spectra of all the examined journals are reported on Table 4.

\section{Further reflections on the h-spectrum}

h-spectrum may have many different practical utilizations, such as:

- providing a "snapshot" of the author population of a specific journal, representing a reference for other (potential) authors. For example, assuming that a (potential) author with $\mathrm{h}=3$ compares himself with the PE authors in 2009, he will fall on the 45th percentile of the corresponding h-spectrum, or another author with $h=1$ will fall on the 24th percentile.

- helping a journal's editorial board to periodically monitor the practical effect of the article selection policy from the point of view of the author population. In this sense, $\mathrm{h}$-spectrum may be interpreted as a signal of editorial strategy. For example, if $\bar{h}$ decreases significantly from one year to the next, it probably means that-among authors - the portion of young researchers or professionals/managers (generally, with small $\mathrm{h}$ values) tends to increase with respect to the portion of senior academics (generally, with high $\mathrm{h}$ values).

- providing a rough indication of one journal's bibliometric positioning on the scientific community. 

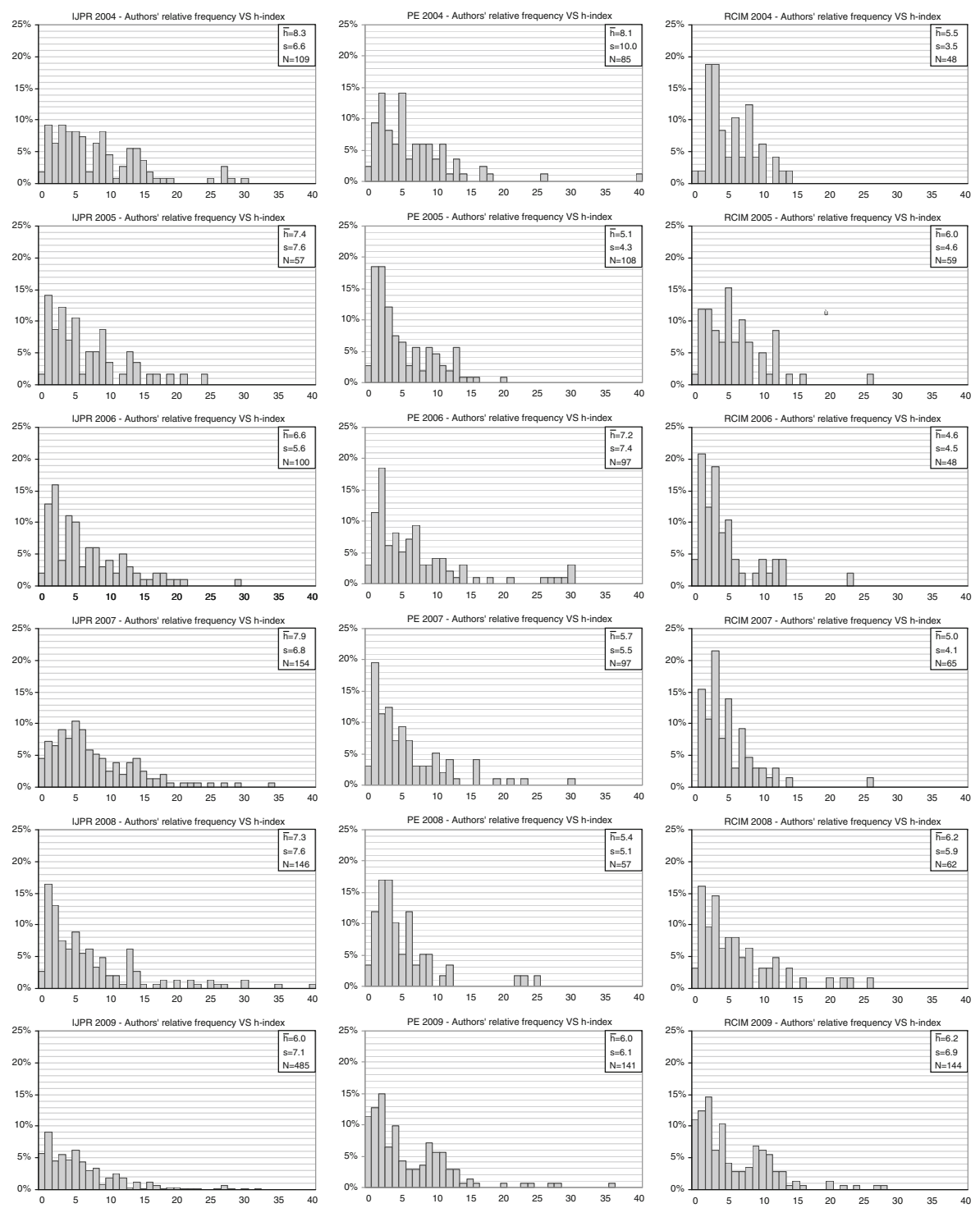

Fig. 8 h-spectra associated to three Manufacturing journals (IJPR, PE and RCIM), in six consecutive years (from 2004 to 2009). For each spectrum, $\overline{\mathrm{h}}, \mathrm{s}$ and $\mathrm{N}$ are reported

The choice of basing this bibliometric tool on $\mathrm{h}$ is due to several reasons. First, $\mathrm{h}$ is simple and able to synthesize the citation distributions of one author into a single number. This is certainly an advantage as managing the full citation distributions of thousands of authors would be very impractical. Secondly, $\mathrm{h}$ is more robust than other synthetic indicators - such as the average number of citations per paper (CPP) or C. This is another important quality, since citation statistics can be subject to different types of database mistakes (such as false references, duplicate records, missing/incomplete data etc.), widely discussed in the literature (Jacso 2006; Bar-Ilan 2008; Bornmann et al. 2009). In particular, 
Table $3 \overline{\mathrm{h}}$, s and $\mathrm{N}$ values for the 23 Manufacturing journals (see Table 1), in six consecutive years (from 2004 to 2009)

\begin{tabular}{|c|c|c|c|c|c|c|c|}
\hline & & 2004 & 2005 & 2006 & 2007 & 2008 & 2009 \\
\hline \multirow[t]{3}{*}{ AA } & $\overline{\mathrm{h}}$ & 3.8 & 5.3 & 4.6 & 6.0 & 3.7 & 5.5 \\
\hline & $\mathrm{s}$ & 3.6 & 5.1 & 4.2 & 6.1 & 3.7 & 6.0 \\
\hline & $\mathrm{N}$ & 57 & 51 & 49 & 63 & 54 & 55 \\
\hline \multirow[t]{3}{*}{ AI EDAM } & $\overline{\mathrm{h}}$ & 8.9 & 7.5 & 9.5 & 7.2 & 8.3 & 8.1 \\
\hline & $\mathrm{s}$ & 7.7 & 5.1 & 7.0 & 6.5 & 7.7 & 7.7 \\
\hline & $\mathrm{N}$ & 32 & 31 & 33 & 40 & 40 & 60 \\
\hline \multirow[t]{3}{*}{ ASM } & $\overline{\mathrm{h}}$ & 6.3 & 6.1 & 5.8 & 4.9 & 4.4 & 5.3 \\
\hline & $\mathrm{s}$ & 5.0 & 5.2 & 4.6 & 4.4 & 4.0 & 5.2 \\
\hline & $\mathrm{N}$ & 140 & 127 & 233 & 214 & 226 & 413 \\
\hline \multirow[t]{3}{*}{ CERA } & $\overline{\mathrm{h}}$ & 9.2 & 7.1 & 4.2 & 7.4 & 5.3 & 4.7 \\
\hline & $\mathrm{s}$ & 7.6 & 6.9 & 3.0 & 6.8 & 4.4 & 6.3 \\
\hline & $\mathrm{N}$ & 38 & 46 & 39 & 46 & 46 & 50 \\
\hline \multirow[t]{3}{*}{ DS } & $\overline{\mathrm{h}}$ & 7.1 & 7.9 & 7.4 & 7.2 & 5.9 & 5.7 \\
\hline & $\mathrm{s}$ & 6.2 & 5.7 & 6.3 & 7.5 & 5.7 & 5.3 \\
\hline & $\mathrm{N}$ & 50 & 42 & 48 & 50 & 54 & 80 \\
\hline \multirow[t]{3}{*}{ HFEM } & $\overline{\mathrm{h}}$ & 6.1 & 5.8 & 6.7 & 4.9 & 5.6 & 5.2 \\
\hline & $\mathrm{s}$ & 4.9 & 5.4 & 6.1 & 5.1 & 6.2 & 6.0 \\
\hline & $\mathrm{N}$ & 35 & 54 & 45 & 45 & 71 & 74 \\
\hline \multirow[t]{3}{*}{ IJAMT } & $\overline{\mathrm{h}}$ & 4.9 & 5.3 & 5.2 & 4.7 & 3.7 & 3.7 \\
\hline & $\mathrm{s}$ & 4.3 & 4.0 & 6.9 & 4.3 & 4.2 & 4.0 \\
\hline & $\mathrm{N}$ & 77 & 137 & 259 & 259 & 331 & 563 \\
\hline \multirow{3}{*}{ IJMTM } & $\overline{\mathrm{h}}$ & 5.4 & 6.0 & 4.9 & 4.8 & 4.4 & 4.4 \\
\hline & $\mathrm{s}$ & 4.0 & 5.1 & 4.0 & 4.8 & 4.2 & 4.3 \\
\hline & $\mathrm{N}$ & 98 & 143 & 143 & 198 & 129 & 223 \\
\hline \multirow[t]{3}{*}{ IJPE } & $\overline{\mathrm{h}}$ & 6.9 & 8.8 & 7.1 & 6.7 & 6.3 & 5.8 \\
\hline & $\mathrm{s}$ & 5.1 & 6.9 & 6.7 & 5.8 & 5.9 & 6.1 \\
\hline & $\mathrm{N}$ & 176 & 185 & 322 & 243 & 459 & 577 \\
\hline \multirow{3}{*}{ IJPR } & $\overline{\mathrm{h}}$ & 8.3 & 7.4 & 6.6 & 7.9 & 7.3 & 6.0 \\
\hline & $\mathrm{s}$ & 6.6 & 7.6 & 5.6 & 6.8 & 7.6 & 7.1 \\
\hline & $\mathrm{N}$ & 109 & 57 & 100 & 154 & 146 & 485 \\
\hline \multirow[t]{3}{*}{ JCISE } & $\overline{\mathrm{h}}$ & 6.5 & 9.9 & 6.2 & 5.7 & 6.2 & 6.1 \\
\hline & $\mathrm{s}$ & 5.5 & 8.6 & 5.6 & 6.2 & 6.2 & 6.5 \\
\hline & $\mathrm{N}$ & 91 & 89 & 80 & 67 & 69 & 112 \\
\hline \multirow[t]{3}{*}{ JIM } & $\overline{\mathrm{h}}$ & 5.1 & 6.3 & 6.1 & 6.1 & 4.6 & 4.1 \\
\hline & $\mathrm{s}$ & 4.6 & 5.9 & 5.8 & 5.9 & 5.0 & 4.8 \\
\hline & $\mathrm{N}$ & 75 & 69 & 88 & 75 & 123 & 133 \\
\hline \multirow[t]{3}{*}{ JMPT } & $\overline{\mathrm{h}}$ & 4.6 & 4.6 & 3.8 & 3.9 & 4.5 & 4.6 \\
\hline & $\mathrm{s}$ & 4.7 & 3.9 & 3.6 & 3.6 & 5.0 & 5.5 \\
\hline & $\mathrm{N}$ & 335 & 567 & 454 & 762 & 1043 & 1095 \\
\hline \multirow[t]{3}{*}{ JMSE } & $\overline{\mathrm{h}}$ & 6.8 & 6.6 & 6.5 & 5.1 & 5.1 & 6.0 \\
\hline & $\mathrm{s}$ & 5.6 & 5.0 & 6.0 & 5.1 & 5.0 & 6.6 \\
\hline & $\mathrm{N}$ & 113 & 94 & 114 & 145 & 135 & 201 \\
\hline
\end{tabular}


Table 3 continued

\begin{tabular}{|c|c|c|c|c|c|c|c|}
\hline & & 2004 & 2005 & 2006 & 2007 & 2008 & 2009 \\
\hline \multirow[t]{3}{*}{ JS } & $\overline{\mathrm{h}}$ & 12.8 & 9.1 & 12.8 & 11.1 & 9.6 & 9.6 \\
\hline & $\mathrm{s}$ & 7.3 & 7.0 & 8.5 & 8.5 & 6.8 & 7.5 \\
\hline & $\mathrm{N}$ & 49 & 46 & 46 & 53 & 83 & 90 \\
\hline \multirow[t]{3}{*}{ MMP } & $\overline{\mathrm{h}}$ & 6.4 & 4.7 & 3.6 & 4.5 & 4.1 & 4.1 \\
\hline & $\mathrm{s}$ & 5.4 & 4.9 & 3.4 & 5.1 & 3.3 & 5.2 \\
\hline & $\mathrm{N}$ & 74 & 58 & 75 & 101 & 18 & 245 \\
\hline \multirow[t]{3}{*}{ MST } & $\overline{\mathrm{h}}$ & 4.8 & 4.1 & 4.8 & 4.0 & 4.8 & 5.0 \\
\hline & $\mathrm{s}$ & 3.4 & 4.5 & 4.1 & 4.0 & 5.8 & 4.9 \\
\hline & $\mathrm{N}$ & 23 & 20 & 27 & 28 & 22 & 27 \\
\hline \multirow[t]{3}{*}{$\mathrm{PE}$} & $\overline{\mathrm{h}}$ & 8.1 & 5.1 & 7.2 & 5.7 & 5.4 & 6.0 \\
\hline & $\mathrm{s}$ & 10.0 & 4.3 & 7.4 & 5.5 & 5.1 & 6.1 \\
\hline & $\mathrm{N}$ & 85 & 108 & 97 & 97 & 57 & 141 \\
\hline \multirow[t]{3}{*}{$\mathrm{POM}$} & $\overline{\mathrm{h}}$ & 8.3 & 7.7 & 8.8 & 11.2 & 11.3 & 10.8 \\
\hline & $\mathrm{s}$ & 5.4 & 5.3 & 5.3 & 8.3 & 8.5 & 9.5 \\
\hline & $\mathrm{N}$ & 36 & 52 & 68 & 51 & 90 & 116 \\
\hline \multirow[t]{3}{*}{ PTS } & $\overline{\mathrm{h}}$ & 6.0 & 4.4 & 4.6 & 5.6 & 4.5 & 3.7 \\
\hline & $\mathrm{s}$ & 5.2 & 3.3 & 4.7 & 5.0 & 4.0 & 4.0 \\
\hline & $\mathrm{N}$ & 52 & 52 & 60 & 77 & 72 & 102 \\
\hline \multirow[t]{3}{*}{ RCIM } & $\overline{\mathrm{h}}$ & 5.5 & 6.0 & 4.6 & 5.0 & 6.2 & 6.2 \\
\hline & $\mathrm{s}$ & 3.5 & 4.6 & 4.5 & 4.1 & 5.9 & 6.9 \\
\hline & $\mathrm{N}$ & 48 & 59 & 48 & 65 & 62 & 144 \\
\hline \multirow[t]{3}{*}{ RED } & $\overline{\mathrm{h}}$ & 9.5 & 9.0 & 7.7 & 7.7 & 7.6 & 8.1 \\
\hline & $\mathrm{s}$ & 8.2 & 8.8 & 5.9 & 6.7 & 6.7 & 6.4 \\
\hline & $\mathrm{N}$ & 20 & 24 & 17 & 23 & 28 & 51 \\
\hline \multirow[t]{3}{*}{ SSMT } & $\overline{\mathrm{h}}$ & 4.5 & 4.5 & 5.7 & 6.6 & 4.9 & 5.5 \\
\hline & $\mathrm{s}$ & 3.3 & 3.3 & 6.2 & 5.8 & 3.3 & 4.5 \\
\hline & $\mathrm{N}$ & 40 & 40 & 32 & 27 & 34 & 60 \\
\hline
\end{tabular}

Journals are sorted in alphabetical order with respect to the respective acronyms

despite the higher coverage, the database in use (i.e. GS) is more prone to these mistakes than other databases. Probably, this comes from the automatic generation of the data set by scanning and parsing PDF files so as to extract reference lists. As a result, data quality of GS is, at present, undoubtedly lower than that one of Web of Science or Scopus (Bar-Ilan 2010). In this sense, the use of $h$ represents a form of protection, since this indicator is less influenced by database mistakes than others. Some practical examples concerning this aspect are presented in a recent short note of Franceschini and Maisano (2010d).

Indeed, $\mathrm{h}$ can be criticized since it crushes the multidimensional space of bibliometrics into one single dimension and has a relatively low discriminative power (Glänzel 2006b, 2010). However, when large-scale evaluations of the scientific production are performed (e.g. over thousands of publications), our opinion is that advantages of $\mathrm{h}$ predominate over disadvantages.

In conclusion, h-spectra can be reliable tools for evaluating a journal at the very moment of the publication, despite the fact that they are based on the publications/citations accumulated before the publication itself. There are empirical proofs of the fact that the citations received 

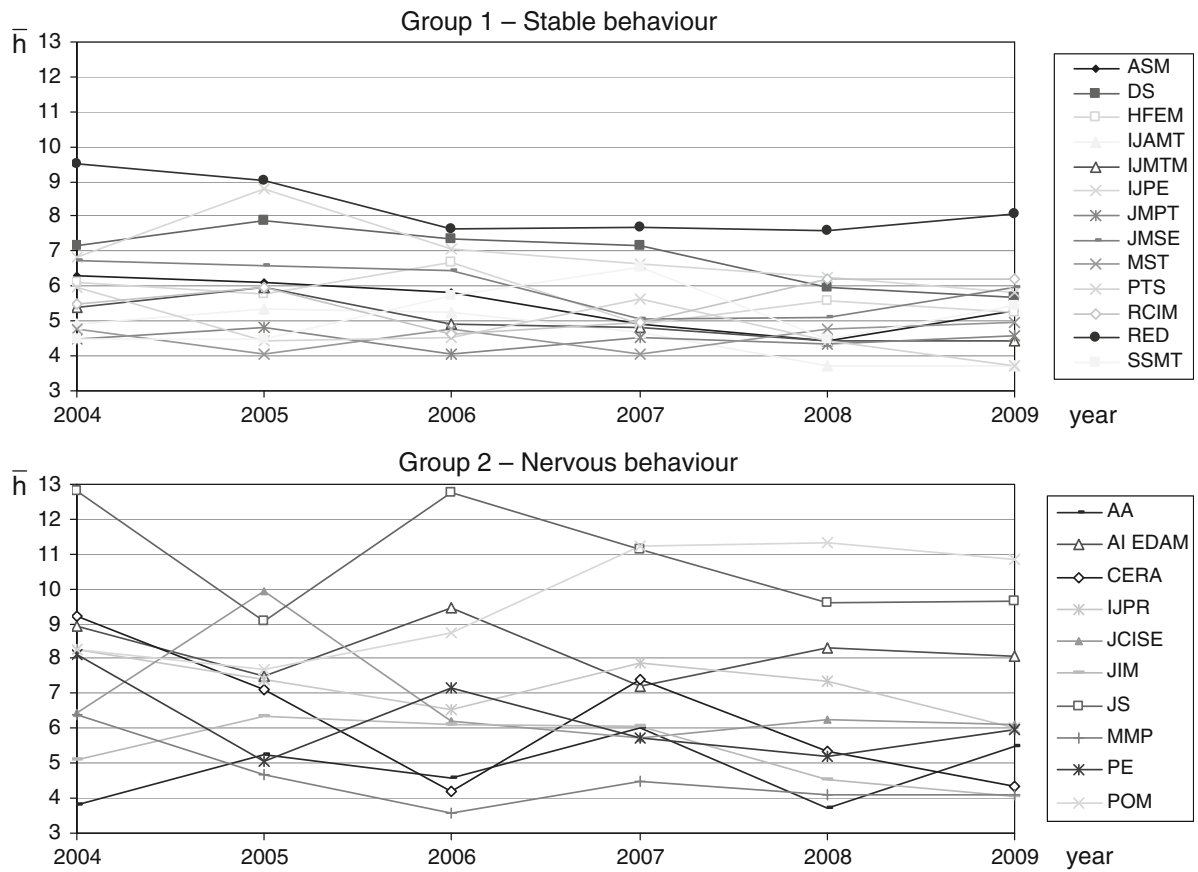

Fig. 9 Graphs showing the $\overline{\mathrm{h}}$ time evolution for the 23 Manufacturing journals (see Table 1), in six consecutive years (from 2004 to 2009). Journal profiles are divided in two groups, according to their qualitative pattern behaviour

by a new article are generally consistent with the citations received by previous articles of the same author, that is to say the author's reputation (Castillo et al. 2007). Being the number of authors per journal quite large (typically more than 40-60 authors per year), it is reasonable to assume that the authors' reputation will be generally respected.

\section{Remarks on the combined use of different bibliometric indicators}

It is worth emphasising the difference between h-spectrum, which is related to the reputation of one journal's authors, and ISI-IF, C, h-for-journal and other traditional bibliometric indicators, which are related to the citations effectively accumulated by one journal's articles. Generally speaking, the academic reputation of a journal's author group is not the equivalent of the reputation of the journal, as well as not the equivalent of the influence of the journal. For this reason, these different indicator typologies are two complementary ways to evaluate/ compare scientific journals. Figure 11 shows the $\overline{\mathrm{h}}$-ISI-IF map, representing an empirical confirmation of the lack of correlation between $\overline{\mathrm{h}}$ and the ISI-IF values $\left(R^{2} \approx 0\right)$.

A combined use of h-spectrum and ISI-IF can be performed for identifying the following situations (Fig. 12 shows the $\overline{\mathrm{h}}$ - ISI-IF map for all the 23 journals for 2008; the corresponding $\overline{\mathrm{h}}$ and ISI-IF values can be found in Tables 2 and 3):

1. Journals with medium-high authors' reputation (in terms of $\overline{\mathrm{h}}$ values) but few received citations (in terms of ISI-IF). This can be the case of relatively recent journals which are still struggling to become popular in the scientific community. 

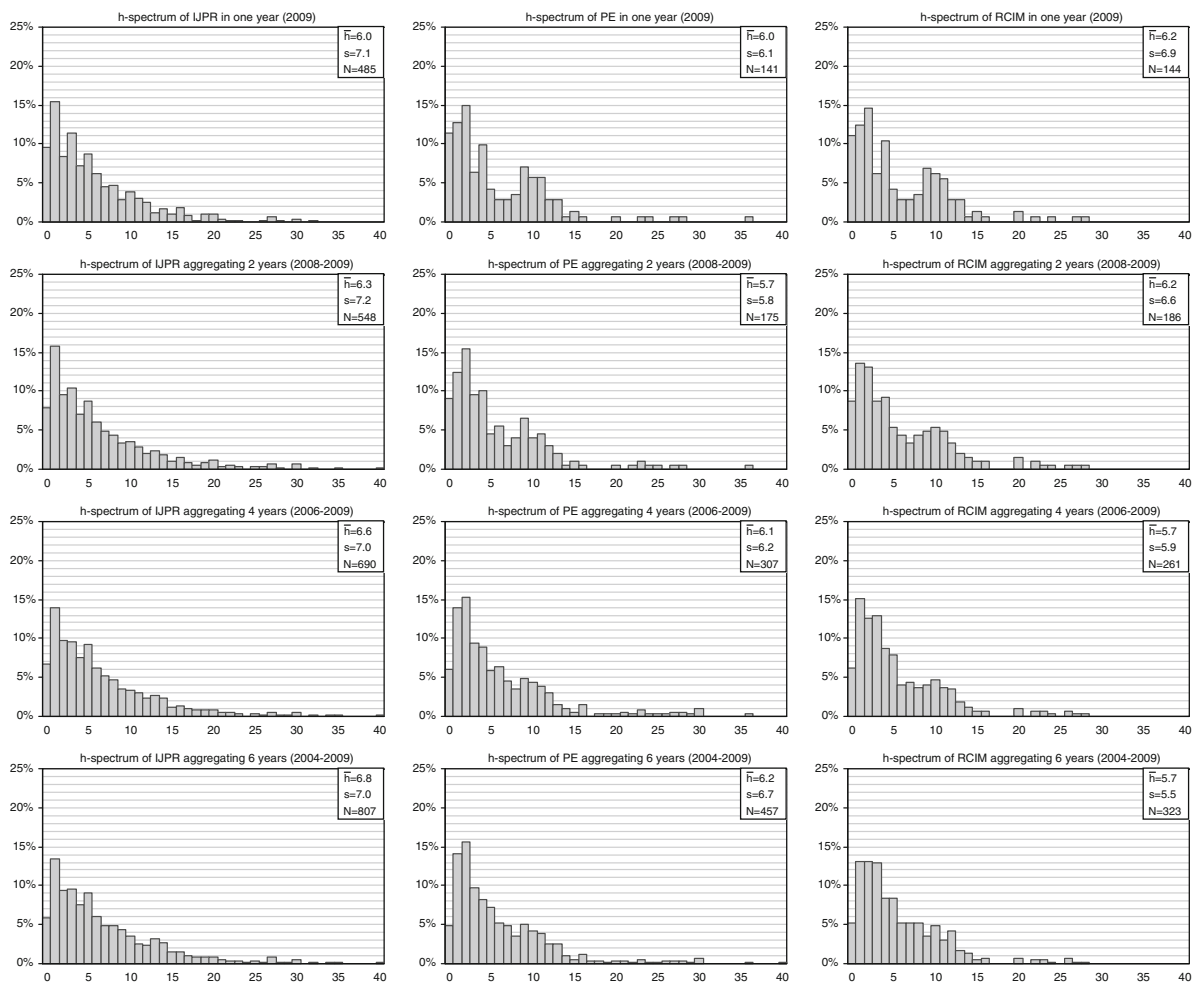

Fig. 10 h-spectra for three Manufacturing journals (IJPR, PE and RCIM), calculated considering four different reference time periods (respectively, 1, 2, 4 and 6 years). For each journal, $\overline{\mathrm{h}}, \mathrm{s}$ and $\mathrm{N}$ values are reported. It can be seen that the larger the time period, the more consolidated the journal's h-spectrum

2. Journals containing articles with a high number of citations, submitted by authors with low h-indexes. This can be the case of journals open beyond the academic world, for instance to professionals and industrial managers. Alternatively, they can be journals with a relatively large group of young authors, consisting of brilliant young researchers with relatively low citation indexes.

A $\bar{h}$-ISI-IF map can be also used for representing the bibliometric positioning of the journals and tracking their evolution over the years; the map in Fig. 13 is constructed for three of the 23 Manufacturing journals, over the 2004-2008 period. Analysing this map we can observe that the general tendency of the journals to increase ISI-IF values is only rarely associated to a tendency to increase $\overline{\mathrm{h}}$ values. For journals that are not indexed by Thomson Scientific, similar maps can be constructed replacing the journal ISI-IF with other citationbased indicators, for example $\mathrm{C}$.

\section{Conclusions}

This paper analyzed 23 of the major journals in the Manufacturing field by four bibliometric indicators: ISI-IF, h-for-journal, citation number and h-spectrum. Differently from 
Table 4 Numerical data ( $\bar{h}, \mathrm{~s}$ and $\mathrm{N}$ values) related to the h-spectra of the 23 examined Manufacturing journals

\begin{tabular}{|c|c|c|c|c|c|}
\hline & & $\begin{array}{l}1 \text { year } \\
(2009)\end{array}$ & $\begin{array}{l}2 \text { years } \\
(2008-2009)\end{array}$ & $\begin{array}{l}4 \text { years } \\
(2006-2009)\end{array}$ & $\begin{array}{l}6 \text { years } \\
(2004-2009)\end{array}$ \\
\hline \multirow[t]{3}{*}{ AA } & $\overline{\mathrm{h}}$ & 5.5 & 4.6 & 5.0 & 4.8 \\
\hline & $\mathrm{s}$ & 6.0 & 5.1 & 5.2 & 5.0 \\
\hline & $\mathrm{N}$ & 55 & 98 & 179 & 249 \\
\hline \multirow[t]{3}{*}{ AI EDAM } & $\overline{\mathrm{h}}$ & 8.1 & 8.2 & 8.2 & 8.2 \\
\hline & $\mathrm{s}$ & 7.7 & 7.7 & 7.3 & 7.1 \\
\hline & $\mathrm{N}$ & 60 & 90 & 135 & 186 \\
\hline \multirow[t]{3}{*}{ ASM } & $\overline{\mathrm{h}}$ & 5.3 & 5.0 & 5.2 & 5.4 \\
\hline & $\mathrm{s}$ & 5.2 & 4.8 & 4.7 & 4.8 \\
\hline & $\mathrm{N}$ & 413 & 593 & 867 & 1118 \\
\hline \multirow[t]{3}{*}{ CERA } & $\overline{\mathrm{h}}$ & 4.7 & 5.0 & 5.4 & 6.3 \\
\hline & $\mathrm{s}$ & 6.3 & 5.5 & 5.5 & 6.2 \\
\hline & $\mathrm{N}$ & 50 & 89 & 153 & 223 \\
\hline \multirow[t]{3}{*}{ DS } & $\overline{\mathrm{h}}$ & 5.7 & 5.8 & 6.4 & 6.7 \\
\hline & $\mathrm{s}$ & 5.3 & 5.4 & 6.1 & 6.1 \\
\hline & $\mathrm{N}$ & 80 & 118 & 195 & 267 \\
\hline \multirow[t]{3}{*}{ HFEM } & $\overline{\mathrm{h}}$ & 5.2 & 5.4 & 5.6 & 5.7 \\
\hline & $\mathrm{s}$ & 6.0 & 6.0 & 6.0 & 5.8 \\
\hline & $\mathrm{N}$ & 74 & 131 & 199 & 259 \\
\hline \multirow[t]{3}{*}{ IJAMT } & $\overline{\mathrm{h}}$ & 3.7 & 3.7 & 4.2 & 4.3 \\
\hline & $\mathrm{s}$ & 4.0 & 4.1 & 4.8 & 4.7 \\
\hline & $\mathrm{N}$ & 563 & 769 & 1148 & 1296 \\
\hline \multirow[t]{3}{*}{ IJMTM } & $\overline{\mathrm{h}}$ & 4.4 & 4.4 & 4.6 & 4.9 \\
\hline & $\mathrm{s}$ & 4.3 & 4.3 & 4.4 & 4.5 \\
\hline & $\mathrm{N}$ & 223 & 319 & 563 & 722 \\
\hline \multirow[t]{3}{*}{ IJPE } & $\overline{\mathrm{h}}$ & 5.8 & 6.0 & 6.3 & 6.6 \\
\hline & $\mathrm{s}$ & 6.1 & 6.0 & 6.1 & 6.2 \\
\hline & $\mathrm{N}$ & 577 & 916 & 1272 & 1517 \\
\hline \multirow[t]{3}{*}{ IJPR } & $\overline{\mathrm{h}}$ & 6.0 & 6.3 & 6.6 & 6.8 \\
\hline & $\mathrm{s}$ & 7.1 & 7.2 & 7.0 & 7.0 \\
\hline & $\mathrm{N}$ & 485 & 548 & 690 & 807 \\
\hline \multirow[t]{3}{*}{ JCISE } & $\overline{\mathrm{h}}$ & 6.1 & 6.2 & 6.1 & 6.8 \\
\hline & $\mathrm{s}$ & 6.5 & 6.4 & 6.1 & 6.7 \\
\hline & $\mathrm{N}$ & 112 & 163 & 282 & 410 \\
\hline \multirow[t]{3}{*}{ JIM } & $\overline{\mathrm{h}}$ & 4.1 & 4.3 & 5.0 & 5.2 \\
\hline & $\mathrm{s}$ & 4.8 & 4.9 & 5.4 & 5.3 \\
\hline & $\mathrm{N}$ & 133 & 221 & 331 & 475 \\
\hline \multirow[t]{3}{*}{ JMPT } & $\overline{\mathrm{h}}$ & 4.6 & 4.5 & 4.4 & 4.5 \\
\hline & $\mathrm{s}$ & 5.5 & 5.1 & 4.7 & 4.7 \\
\hline & $\mathrm{N}$ & 1095 & 1928 & 2779 & 3231 \\
\hline \multirow[t]{3}{*}{ JMSE } & $\overline{\mathrm{h}}$ & 6.0 & 5.6 & 5.6 & 5.9 \\
\hline & $\mathrm{s}$ & 6.6 & 6.0 & 5.8 & 5.7 \\
\hline & $\mathrm{N}$ & 201 & 308 & 506 & 609 \\
\hline
\end{tabular}


Table 4 continued

\begin{tabular}{|c|c|c|c|c|c|}
\hline & & $\begin{array}{l}1 \text { year } \\
(2009)\end{array}$ & $\begin{array}{l}2 \text { years } \\
(2008-2009)\end{array}$ & $\begin{array}{l}4 \text { years } \\
(2006-2009)\end{array}$ & $\begin{array}{l}6 \text { years } \\
(2004-2009)\end{array}$ \\
\hline \multirow[t]{3}{*}{ JS } & $\overline{\mathrm{h}}$ & 9.6 & 9.6 & 10.5 & 10.6 \\
\hline & $\mathrm{S}$ & 7.5 & 7.2 & 7.7 & 7.6 \\
\hline & $\mathrm{N}$ & 90 & 149 & 224 & 300 \\
\hline \multirow[t]{3}{*}{ MMP } & $\overline{\mathrm{h}}$ & 4.1 & 4.1 & 4.1 & 4.5 \\
\hline & $\mathrm{s}$ & 5.2 & 5.1 & 4.9 & 5.0 \\
\hline & $\mathrm{N}$ & 245 & 239 & 345 & 472 \\
\hline \multirow[t]{3}{*}{ MST } & $\overline{\mathrm{h}}$ & 5.0 & 4.9 & 4.6 & 4.6 \\
\hline & $\mathrm{s}$ & 4.9 & 5.3 & 4.6 & 4.4 \\
\hline & $\mathrm{N}$ & 27 & 47 & 89 & 116 \\
\hline \multirow[t]{3}{*}{$\mathrm{PE}$} & $\overline{\mathrm{h}}$ & 6.0 & 5.7 & 6.1 & 6.2 \\
\hline & $\mathrm{s}$ & 6.1 & 5.8 & 6.2 & 6.7 \\
\hline & $\mathrm{N}$ & 141 & 175 & 307 & 457 \\
\hline \multirow[t]{3}{*}{ POM } & $\overline{\mathrm{h}}$ & 10.8 & 11.0 & 10.6 & 10.1 \\
\hline & $\mathrm{s}$ & 9.5 & 9.1 & 8.3 & 7.8 \\
\hline & $\mathrm{N}$ & 116 & 194 & 277 & 335 \\
\hline \multirow[t]{3}{*}{ PTS } & $\overline{\mathrm{h}}$ & 3.7 & 4.0 & 4.5 & 4.7 \\
\hline & $\mathrm{S}$ & 4.0 & 4.0 & 4.4 & 4.4 \\
\hline & $\mathrm{N}$ & 102 & 162 & 264 & 349 \\
\hline \multirow[t]{3}{*}{ RCIM } & $\overline{\mathrm{h}}$ & 6.2 & 6.2 & 5.7 & 5.7 \\
\hline & $\mathrm{s}$ & 6.9 & 6.6 & 5.9 & 5.5 \\
\hline & $\mathrm{N}$ & 144 & 186 & 261 & 323 \\
\hline \multirow[t]{3}{*}{ RED } & $\overline{\mathrm{h}}$ & 8.1 & 7.9 & 7.8 & 8.2 \\
\hline & $\mathrm{s}$ & 6.4 & 6.4 & 6.3 & 7.0 \\
\hline & $\mathrm{N}$ & 51 & 74 & 94 & 134 \\
\hline \multirow[t]{3}{*}{ SSMT } & $\overline{\mathrm{h}}$ & 5.5 & 5.1 & 5.5 & 5.1 \\
\hline & $\mathrm{s}$ & 4.5 & 4.1 & 4.9 & 4.4 \\
\hline & $\mathrm{N}$ & 60 & 83 & 130 & 194 \\
\hline
\end{tabular}

Journals are sorted in alphabetical order with respect to the corresponding acronyms. Data are evaluated considering four different reference time periods (respectively, 1, 2, 4 and 6 years)

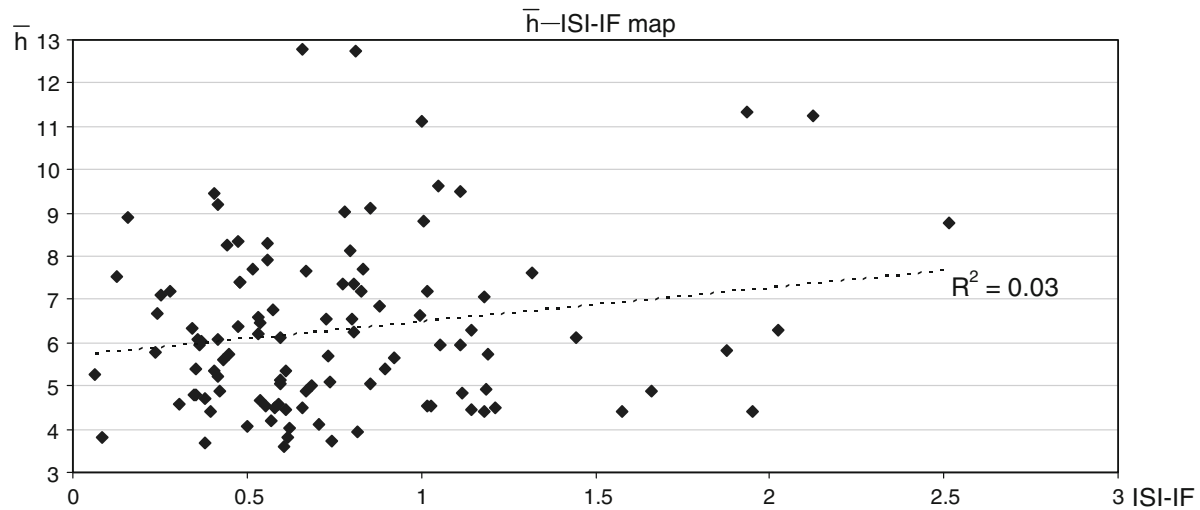

Fig. 11 Graph representing $\overline{\mathrm{h}}$ values (vertical axis) against ISI-IF values (horizontal axis), using the data related to the 23 manufacturing journals (see Tables 2 and 3), in the 2004-2008 period. The lack of correlation between the two different indicators is clear $\left(R^{2} \approx 0\right)$ 


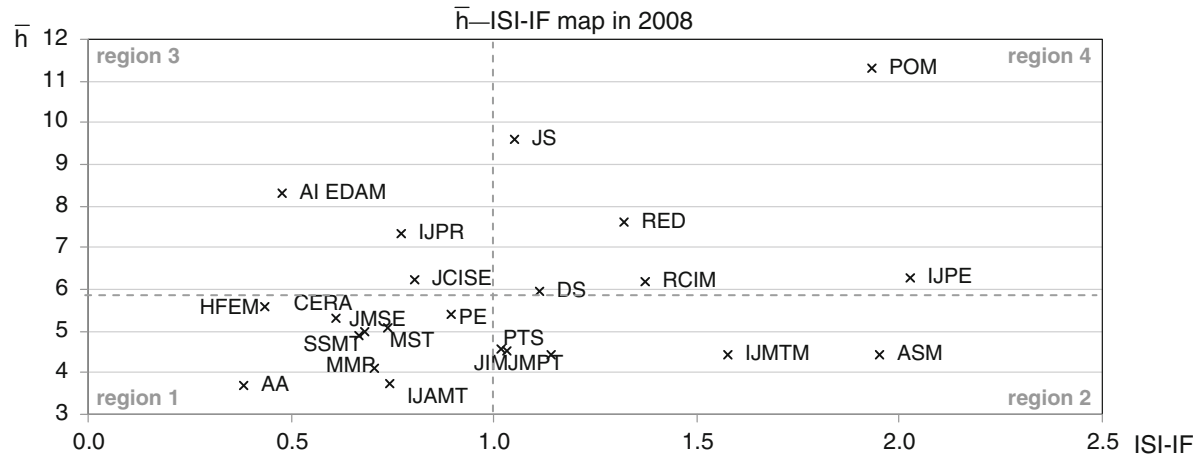

Fig. 12 Example of a simplified map for comparing journals on the basis of different bibliometric indicators. The map associates $\overline{\mathrm{h}}$ values (vertical axis) with ISI-IF values (horizontal axis) and makes it possible to identify different regions: (1) journals with low authors' reputation (in terms of $\overline{\mathrm{h}}$ values) and few received citations (in terms of ISI-IF values); (2) journals containing articles with a high number of citations, submitted by authors with low h-indexes; (3) journals with medium-high authors' reputation but few received citations and (4) journals containing articles with a high number of citations, submitted by authors with high h-indexes

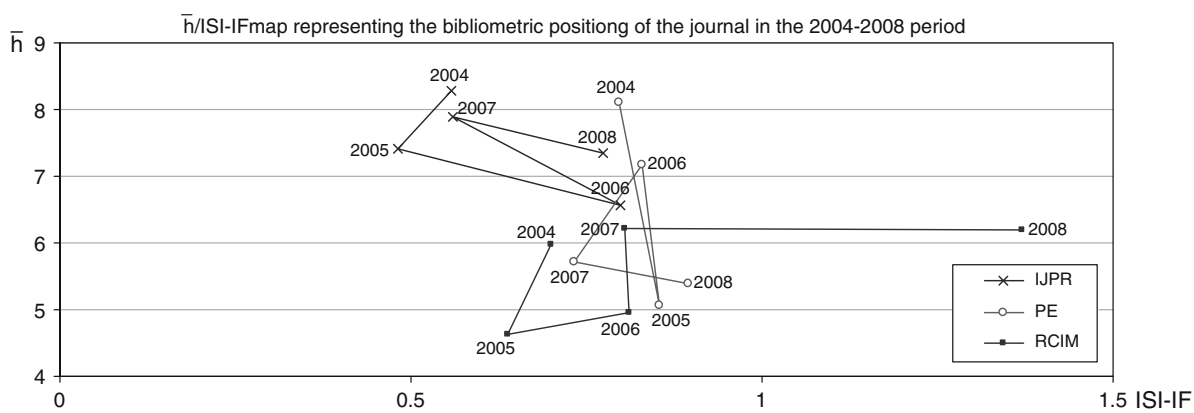

Fig. $13 \bar{h}$-ISI-IF map for three manufacturing journals in the 2004-2008 period. The corresponding $\bar{h}$ and ISI-IF values are shown in Tables 2 and 3

ISI-IF, the three other indicators can be applied to every kind of journal—not necessarily those indexed by Thomson Scientific or other organizations. Citation statistics are collected using the GS freeware search engine.

One novelty of this paper is the intensive use of the h-spectrum, a recent indicator based on the h-index. It is interesting to observe that the h-spectrum has a peculiar shape and it is rather robust over the years. Furthermore, it can be calculated at the very moment of the journal publication, unlike ISI-IF (which is calculated 1-2 years after the publication), h-for-journal and C. Differently from h-for-journal and C, h-spectrum does not tend to favour journals with many articles/issues per year.

The bibliometric analysis we proposed can be helpful for different reasons: (i) it provides a reference for the (potential) authors of the major scientific journal on Manufacturing sector; (ii) it makes it possible to perform rough comparisons between different journals and estimate their bibliometric positioning; (iii) it supports a journal's editorial staff to periodically monitor the effect of the paper selecting policy. 
Of particular interest is the construction of the $\overline{\mathrm{h}}$ - ISI-IF map to compare journals and monitor their bibliometric positioning over time.

Several ideas for further research activities may originate from this work. It would be interesting to extend the analysis to a wider set of Manufacturing journals (including those not indexed by Thomson Reuters) and to other disciplines - such as industrial engineering and mechanical and aerospace engineering — and define a guideline for ranking journals by using several bibliometric indicators in a structured way.

Acknowledgments Authors would like to thank Yan Li for data collecting, Andrea Proto for the construction of an ad hoc software to query GS, and Dr Luca Mastrogiacomo for his suggestions about cluster analysis.

\section{References}

Alonso, S., Cabrerizo, F. J., Herrera-Viedma, E., \& Herrera, F. (2009). h-Index: A review focused in its variants, computation and standardization for different scientific fields. Journal of Informetrics, 3(4), 273-289.

Althouse, B. M., West, J. D., Bergstrom, T., \& Bergstrom, C. T. (2010). Differences in impact factor across fields and over time. http://arxiv.org/abs/0804.3116v1. Accessed Feb 102010.

Amin, M., \& Mabe, M. (2000). Impact factors: Use and abuse. Oxford: Elsevier.

Antonakis, J., \& Lalive, R. (2008). Quantifying scholarly impact: IQp versus the Hirsch h. Journal of the American Society for Information Science and Technology, 59(6), 956-969. doi:10.1002/asi.v59:6.

Banks, M. G. (2006). An extension of the Hirsch index: Indexing scientific topics and compounds. Scientometrics, 69(1), 161-168. doi:10.1007/s11192-006-0146-5.

Bar-Ilan, J. (2008). Which h-index?-A comparison of WoS, Scopus and Google Scholar. Scientometrics, $74(2), 257-271$.

Bar-Ilan, J. (2010). Citations to the "Introduction to informetrics" indexed by WoS, Scopus and Google Scholar. Scientometrics, 82(3), 495-506.

Batista, P. D., Campiteli, M. G., Kinouchi, O., \& Martinez, A. S. (2006). Is it possible to compare researchers with different scientific interests? Scientometrics, 68(1), 179-189. doi:10.1007/ s11192-006-0090-4.

BiHui, J., LiMing, L., Rousseau, R., \& Egghe, L. (2007). The R- and AR-indices: Complementing the h-index. Chinese Science Bulletin, 52(6), 855-963. doi:10.1007/s11434-007-0145-9.

Bornmann, L., \& Daniel, H. D. (2007). What do we know about the h index? Journal of the American Society for Information Science and Technology, 58(9), 1381-1385. doi:10.1002/asi.20609.

Bornmann, L., Marx, W., Schier, H., Rahm, E., Thor, A., \& Daniel, H. D. (2009). Convergent validity of bibliometric Google Scholar data in the field of chemistry-Citation counts for papers that were accepted by Angewandte Chemie International Edition or rejected but published elsewhere, using Google Scholar, Science Citation Index, Scopus, and Chemical Abstracts. Journal of Informetrics, 3(1), 27-35.

Braun, T., Glänzel, W., \& Schubert, A. (2006). A Hirsch-type index for journals. The Scientist, 69(1), 169-173. doi:10.1007/s11192-006-0147-4.

Burrell, Q. L. (2002). The nth-citation distribution and obsolescence. Scientometrics, 53(3), 309-323.

Burrell, Q. L. (2007). Hirsch index or Hirsch rate? Some thoughts arising from Liang's data. Scientometrics, 73(1), 19-28. doi:10.1007/s11192-006-1774-5.

Castillo, C., Donato, D., \& Gionis, A. (2007). Estimating number of citations using author reputation. In N. Ziviani \& R. Baeza-Yates (Eds.), String processing and information retrieval (pp. 107-117). Berlin/ Heidelberg: Springer. doi:10.1007/978-3-540-75530-2_10.

Costas, R., \& Bordons, M. (2007). The h-index: Advantages, limitations and its relation with other bibliometric indicators at the micro level. Journal of Informetrics, 1(3), 193-203. doi:10.1016/j.joi. 2007.02.001.

Egghe, L. (2006). Theory and practise of the g-index. Scientometrics, 69(1), 131-152. doi:10.1007/s11192006-0144-7.

Egghe, L. (2010). The Hirsch-index and related impact measures. In B Cronin (Ed.), Annual Review of Information Science and Technology (ARIST) (Vol. 44, pp. 65-114). Information Technology Inc., ISBN 978-1-57387-371-0. 
Egghe, L., \& Ravichandra Rao, I. K. (2001). Theory of first-citation distributions and applications. Mathematical and Computer Modelling, 34(1-2), 81-90.

Franceschini, F., Galetto, M., \& Maisano, D. (2007). Management by measurement: Designing key indicators and performance measurement systems. Berlin: Springer.

Franceschini, F., \& Maisano, D. (2009). The Hirsch index in manufacturing and quality engineering. Quality and Reliability Engineering International, 25, 987-995. doi:10.1002/qre.1016.

Franceschini, F., \& Maisano, D. (2010a). A survey of Quality Engineering-Management journals by bibliometric indicators. Quality and Reliability Engineering International, 26(6), 593-604. doi: 10.1002/qre.1083.

Franceschini, F., \& Maisano, D. (2010b). The Hirsch spectrum: A novel tool for analysing scientific journals. Journal of Informetrics, 4(1), 64-73. doi:10.1016/j.joi.2009.08.003.

Franceschini, F., \& Maisano, D. (2010c). Analysis of the Hirsch index's operational properties. European Journal of Operational Research, 203(2), 494-504. doi:10.1016/j.ejor.2009.08.001.

Franceschini, F., \& Maisano, D. (2010d). Influence of database mistakes on journal citation analysis: Remarks on Franceschini and Maisano QREI (2010) paper. Quality and Reliability Engineering International (to appear).

Franceschini, F., Maisano, D., Perotti, A., \& Proto, A. (2010). Analysis of the ch-index: an indicator to evaluate the diffusion of scientific research output by citers. Scientometrics, 85(1), 203-217. doi: 10.1007/s11192-010-0165-0.

Garfield, E. (2005). Agony and the ecstasy - the history and meaning of the impact factor. In Proceedings of the International Congress on Peer review and Biomedical Publication, Chicago, 16 Sep 2005.

Garfield, E. (2006). The history and meaning of the journal impact factor. Journal Of the American Medical Association, 295(1), 90-93.

Glänzel, W. (2006a). On the opportunities and limitations of the h-index. Science Focus, 1(1), 10-11.

Glänzel, W. (2006b). On the h-index-A mathematical approach to a new measure of publication activity and citation impact. Scientometrics, 67(2), 315-321.

Glänzel, W. (2010). The role of the h-index and the characteristic scores and scales in testing the tail properties of scientometric distributions. Scientometrics, 83(3), 697-709.

Glänzel, W., \& Schubert, A. (2010). Hirsch-type characteristics of the tail of distributions. The generalised h-index. Journal of Informetrics, 4(1), 118-123.

Harzing, A. W. (2010). Reflections on the h-index. www.harzing.com. Accessed 10 Feb 2010.

Harzing, A. W., \& van der Wal, R. (2008). Google Scholar as a new source for citation analysis. Ethics in Science and Environmental Politics, 8(11), 61-73.

Hirsch, J. E. (2005). An index to quantify an individual's scientific research output. Proceedings of the National Academy of Sciences of the United States of America, 102, 16569-16572. doi: 10.1073/pnas.0507655102.

Hirsch, J. E. (2007). Does the h index have predictive power? Proceedings of the National Academy of Sciences of the United States of America, 104(49), 19193-19198. doi:10.1073/pnas.0707962104.

Jacso, P. (2006). Deflated, inflated and phantom citation counts. Online Information Review, 30(3), 297-309.

JCQAR-Joint Committee on Quantitative Assessment of Research. (2010). Citation statistics. http://www.mathunion.org/fileadmin/IMU/Report/CitationStatistics.pdf. Accessed 10 Feb 2010.

Katsaros, D., Sidiropoulos, A., \& Manolopous, Y. (2007). Age decaying H-index for social network of citations. In Proceedings of Workshop on Social Aspects of the Web, Poznan, Poland.

Kelly, C. D., \& Jennions, M. D. (2006). The h index and career assessment by numbers. Trends in Ecology \& Evolution, 21(4), 167-170. doi:10.1016/j.tree.2006.01.005.

Lehmann, S., Jackson, A. D., \& Lautrup, B. E. (2010). Measures and mismeasures of scientific quality. http://arxiv.org/abs/physics/0512238. Accessed 10 Feb 2010.

Leydesdorff, L. (2009). How are new citation-based journal indicators adding to the bibliometric toolbox? Journal of the American Society for Information Science \& Technology, 60(7), 1327-1336.

Mingers, J. (2009). Measuring the research contribution of management academics using the Hirsch-index. Journal of the Operational Research Society, 60(9), 1143-1153. doi:10.1057/jors.2008.94.

Moed, H. F. (2005). Citation analysis in research evaluation. Springer: Dordrecht.

Orbay, M., Karamustafaoglu, O., \& Oner, F. (2007). What does Hirsch index evolution explain us? A case study: Turkish Journal of Chemistry. Biblios, 27(8), 1-5.

Rousseau, R. (2010). New developments related to the Hirsch index. E-prints in Library and Information Science (ELIS). www.eprints.rclis.org. Accessed 10 Feb 2010.

Saad, G. (2006). Exploring the h-index at the author and journal levels using bibliometric data of productive consumer scholars and business-related journals respectively. Scientometrics, 69(1), 117-120.

Schreiber, M. (2007). Self-citation corrections for the Hirsch index. Euro Physics Letters, 78, 1-6. doi: $10.1209 / 0295-5075 / 78 / 30002$. 
Schreiber, M. (2010). Modification of the h-index: The $\mathrm{h}_{\mathrm{m}}$-index accounts for multi-authored manuscripts. http://arxiv.org/abs/0805.2000v1. Accessed 10 Feb 2010.

Scopus-Elsevier. (2010). www.info.scopus.com. Accessed 10 Feb 2010.

Sidiropoulos, A., Katsaros, D., \& Manolopoulos, Y. (2007). Generalized Hirsch h-index for disclosing latent facts in citation networks. Scientometrics, 72(2), 253-280. doi:10.1007/s11192-007-1722-z.

ThomsonReuters. (2010). www.thomsonreuters.com/products_services/scientific/Journal_Citation_Reports. Accessed 10 Feb 2010.

Van Raan, A. F. J. (2006). Comparison of the Hirsch-index with standard bibliometric indicators and with peer judgment for 147 chemistry research groups. Scientometrics, 67(3), 491-502. doi:10.1007/ s11192-006-0066-4.

Wendl, M. (2007). H-index however ranked, citations need context. Nature, 449, 403. doi:10.1038/449403b.

Woeginger, G. H. (2008). An axiomatic characterization for the Hirsch-index. Mathematical Social Sciences, 56, 224-232. doi:10.1016/j.mathsocsci.2008.03.001. 